\title{
Mental Capacity Assessments for COVID-19 Patients: Emergency Admissions and the CARD Approach
}

\author{
Cameron Stewart 1 - Paul Biegler - Scott Brunero • \\ Scott Lamont • George F. Tomossy
}

Received: 26 May 2020 / Accepted: 23 September 2020

(C) Journal of Bioethical Inquiry Pty Ltd. 2020
Keywords Capacity · Consent · COVID-19. Emergency admission

\section{Introduction-COVID-19 Patients}

Coronavirus disease 2019 (COVID-19) is caused by the severe acute respiratory syndrome coronavirus 2 (SARS-CoV-2)(Jiang 2020). Patients with COVID-19 present with symptoms and signs that include fever, cough, dyspnoea, fatigue, anorexia, anosmia, myalgia, and confusion (Thevarajan, Buising, and Cowie 2020). About 80 per cent of infections are mild and do not require hospitalization but around 15 per cent of infected patients need hospital care and 5 per cent require intensive support (Thevarajan, Buising, and Cowie 2020). COVID-19 disproportionately affects the elderly, who have a much higher risk of severe disease, hospitalization, and death (Holt et al. 2020; Onder, Rezza and Brusaferro 2020). The increased demand for critical and palliative care caused by the pandemic has placed pressure on practitioners to manage key aspects of the therapeutic relationship. Anaesthetists, for example, "will require enhanced skills in discussing goals of care, managing symptoms in the dying patient and withdrawing life-sustaining measures" (Mottiar et al. 2020, 1417).

Gaining consent from COVID-19 patients may be difficult if they are severely short of breath, in pain, or confused (D'Souza et al. 2019). Delirium has been recognized as a "presenting feature of COVID-19, particularly in patients of advanced age," expressed as 
"acute, fluctuating consciousness and temporary cognitive impairment" (Parsons and Johal 2020, 447). Valid consent requires an appropriate standard of information provision and of voluntariness and, crucially, for patients to demonstrate the capacity to make decisions about their medical treatment (Lamont, Stewart, and Chiarella 2016a, 2016b).

Studies have shown that some healthcare practitioners lack sufficient knowledge to assess capacity, including in emergency and intensive care settings (Bertrand et al. 2019; Chan et al. 2018; Evans, Warner, and Jackson 2007). Similar knowledge deficits have been identified in acute generalist settings (Lamont, Stewart, and Chiarella 2019). Capacity screening and assessment have also been found to be deficient in vunerable populations where incapacity is more likely, such as people with mental illness or cognitive impairment (Lamont, Stewart, and Chiarella 2016a). Even when assessments are performed, they may be poorly implemented and overestimate patients' capacity (Raymont et al. 2004). One potential reason for these problems may be generalist healthcare practitioners lacking education about capacity testing (Lamont, Jeon, and Chiarella 2013a).

The combination of very sick patients, knowledge deficits, and high pressure environments is likely to make capacity assessment very difficult during the COVID-19 pandemic (Parsons and Johal 2020; Keene 2020). Poor capacity assessment may result in competent patients being treated against their will or incapacitated patients not being treated appropriately as they fail to receive treatment in accordance with the emergency doctrine (also known as the doctrine of necessity) or via the consent of legal substitute decision-makers (Kerridge, Lowe, and Stewart 2013). In this article we define mental capacity, restate the legal test, and provide practical advice on how to assess the capacity of COVID-19 patients in emergency and critical care settings, including a short list of questions which flag capacity issues which we refer to as the CARD approach.

\section{What is Mental Capacity?}

Mental capacity is the functional ability of a person to make decisions about healthcare, an attribute that reflects the central ethical principle of personal autonomy (Kerridge, Lowe, and Stewart 2013). Capacity forms the basis of the legal doctrines of consent to treatment (the process of gaining permission to treat) and informed consent (the duty to provide material information regarding the nature, purpose, benefits, and risks of having or not having treatment (see Reiblv Hughes [1980] 2 SCR 880; Rogers $v$ Whitaker (1992) 175 CLR 479, 490; Montgomery v Lanarkshire Health Board [2015] UKSC 1; Fitzpatrick $v$ White [2007] IESC 51).

In common law, all adults are presumed to have mental capacity, whereas children are presumed not to have mental capacity (Re T (adult: refusal of medical treatment) [1992] 4 All ER 649). These presumptions are rebuttable and may be overridden by evidence that an adult lacks capacity or that a child has capacity (Gillick $v$ West Norfolk and Wisbech Area Health Authority [1986] AC 112).

The common law test for mental capacity, which emerged from the case of Re C (Adult: Refusal of Treatment) [1994] 1 WLR 290 (see Box 1), requires a patient to be able to

1. understand treatment information,

2. retain the information,

3. weigh the information as part of a process of decision-making, and

4. communicate the decision to others.

Box 1 Case examples of mental capacity disputes

Re C (Adult: Refusal of Treatment) [1994] 1 WLR 290. In this English case, $\mathrm{C}$ was a 68 year old man with schizophrenia who was a long-term resident of what is now known as the Broadmoor Hospital. C developed gangrene of the foot and surgeons recommended a below knee amputation. $\mathrm{C}$ refused amputation on the basis he would rather die with two legs than live with one. $\mathrm{C}$ had a delusion that he was an internationally famous doctor. Despite this, Thorpe J found C competent to refuse treatment on the basis that he could comprehend and retain relevant information, believe it, and weigh it in the balance to arrive at a choice. Thorpe $\mathrm{J}$ found that the delusions did not impact on C's ability to perform these tasks.

$\operatorname{Re} M B$ [1997] 2 FCR 541. MB had consented to an emergency caesarean section, but she suffered needle phobia and resisted the administration of anaesthetics. Anaesthesia by mask was attempted but was unsuccessful. Further attempts to use a needle failed, even though MB continued to consent to the procedure. Doctors sought an order to permit them to forcibly provide the anaesthetic. The Court of Appeal of England and Wales found that MB's phobia meant that she was "incapable of making a decision at all" and treatment was approved.

Brightwater Care Group Inc v Rossiter [2009] WASC 229. In this Australian case, Rossiter was a quadriplegic who was 
dependent on artificial feeding and hydration through a feeding tube (PEG). Rossiter expressed a desire to refuse feeding and die. He gave numerous directions to carers to cease feeding and hydration. The Supreme Court of Western Australia found that it would be lawful to withdraw treatment as Rossiter's capacity was attested to by several experts including a clinical neuropsychologist.

Auckland Area Health Board v Attorney-General [1993] 1 NZLR 235. A patient with Guillain-Barre Syndrome (a condition which impairs communication through progressive paralysis but does not impair cognition) was presumed to be incompetent by the court seemingly because of his inability to communicate

Fitzpatrick v K [2008] IEHC 104. An African woman living in Ireland haemorrhaged after giving birth. After emergency treatment had commenced the staff were told by the patient that she was a Jehovah's Witness and that she refused blood (on admission she had claimed to be a Roman Catholic). The patient suggested that she should be given Coca-Cola, tomatoes, eggs, and milk as an alternative to blood products. The treating obstetrician doubted the patient's capacity to make a decision and approached the court for a determination on capacity and for an order authorizing treatment in the interim. These orders were made. The woman later appealed the decision. The court found that, while the patient may have been competent to refuse treatment, at the time there was sufficient uncertainty with regards to the patient's ability to retain and understand information to justify the court order.

This test is part of the common law of Australia, Canada, Ireland, New Zealand, Singapore, the United Kingdom, and the United States. It also features in healthcare and guardianship legislation in all jurisdictions in Australia, apart from Western Australia (see for example the Medical Treatment Planning and Decisions Act 2016 (Vic), s 4), the provinces of Canada (see, for example, Adult Capacity and Decisionmaking Act, SNS 2017, c 4 s 3(d)), England and Wales (Mental Capacity Act 2005, ss 2, 3), Scotland (The Adults with Incapacity (Scotland) Act 2000, s 1(6)), Northern Ireland (Mental Capacity Act (Northern Ireland) 2016, s 4), Ireland (Assisted Decision-Making (Capacity) Act 2015, s 3(2)), New Zealand (Protection of Personal and Property Rights Act 1988, s 6), and Singapore (Mental Capacity Act 2008 (Chapter 177A), s 5).

More than ten years ago, many of these jurisdictions (including, Australia, Canada, Ireland, Singapore, and the United Kingdom) became signatories to the Convention of the Rights of Persons with Disabilities 2008 which, in Article 12(2), states that all people should be treated as enjoying "equal legal capacity." Some commentators took this to mean that capacity testing should be abolished, but none of the signatories above have done so, and the standard legal capacity test has been retained in these jurisdictions (Stewart 2017).

Mental capacity should be assessed in adult patients with signs of impaired consciousness or cognition, including from head injury, drugs or alcohol, dementia, delirium, and mental illness (Biegler and Stewart 2001). Other relevant factors include high levels of pain and discomfort, shock, fatigue, panic, and fear. The potential for these factors to undermine the validity of consent means COVID-19 patients who present with them should have their capacity assessed.

A number of factors impacting on decision-making ability should be ameliorated prior to a capacity assessment. Emergency departments, for example, are often loud and stressful and so providing a quiet place, with family or support persons present, may help patients listen to and process information. Information should also be conveyed as clearly as possible (Jacob et al. 2005; UN General Assembly, Convention on the Rights of Persons with Disabilities A/RES/61/106, resolution adopted January 24, 2007). Visual aids can and should be used and translation services should be employed for non-English speaking patients.

A large number of capacity instruments, tools, and tests are available, although a variety of limitations exist which affect their clinical utility (Lamont, Jeon, and Chiarella 2013b). Importantly, tests such as the minimental status examination (MMSE) are designed to assess cognition and not capacity (Lamont, Jeon, and Chiarella 2013b). Cognitive tests may be useful screening tools - a lower MMSE score increases the chance a patient lacks capacity-but they are not diagnostic (Stewart and Biegler 2004).

Arguably, the most widely tested and used capacity assessment instrument is the Macarthur Competency Assessment Tool for Treatment (MacCATT) (Grisso and Appelbaum 1998). A recent study found that the MacCAT-T closely corresponded with the legal test of capacity (Curley et al. 2019). A difficulty with the MacCAT-T test is, however, that it takes around twenty minutes to complete, which may be impracticable in emergency and critical care settings. Evidently, an alternative method is needed. 
The CARD Approach-Comprehend, Appreciate, Reason, and Decide

We recommend that in emergency admissions for COVID-19 a simple set of questions be asked of patients to assess mental capacity (box 2). The acronym CARD (comprehend, appreciate, reason, and decide) makes these questions easy for health professionals to remember. The questions under each heading correspond to each step of the legal test for capacity which will now be discussed.

Box 2 The CARD approach

\section{Comprehend (Understand)}

"Please tell me what you understand about your condition"

"What do you think is wrong with you?"

"What have you been told about treatment?"

\section{Appreciate (Retain) \\ "What is the treatment likely to do for you? Why do you think it will have that effect?" \\ "What do you believe will happen if you are not treated" \\ "Why do you think we have recommended this treatment for you?" \\ "Can you recall what you were told about the risks and benefits of treatment?"}

\section{Reason (Weigh)}

"Tell me how you reached the decision to accept (reject) treatment?"

"What things were important to you in reaching the decision?"

"How do you balance those things?"

Decide (Communicate)

"Have you decided whether to go along with our suggested treatment?"

"Can you tell me what your treatment decision is?"

\section{Comprehend: Understanding Treatment Information}

The first component of the legal test requires the patient to understand information relating to the diagnosis and treatment options. This approach assumes the patient has been given the information in a way he or she could be reasonably expected to comprehend.

The level and detail of information that should be provided to test capacity is a subject of controversy (Stewart and Biegler 2004; Cave 2020). On one view, the patient needs to understand only basic information regarding the nature and purpose of the proposed treatment; this is the standard of information that protects a health professional from accusations of battery in criminal and tort law. But, as stated above, health professionals also need to provide information about "material" risks to satisfy an informed consent standard, which may demand more detail about treatment. The question is whether the bar for mental capacity should be set at the higher or lower level.

To satisfy the informed consent standard, patients must be given information about material risks. A risk is material if

1. in the circumstances of the case, a reasonable person in the patient's position would be likely to attach significance to it ("the objective limb"); or

2. the medical practitioner was, or should have been, aware that the particular patient would be likely to attach significance to it ("the subjective limb") (Rosenberg v Percival (2001) 205 CLR 434 at [75]).

The extra level of detail required by informed consent heightens the chance that patients will fail to meet the "understanding" requirement of the capacity test, an outcome made more likely in emergency and critical care settings by time pressure and the discomfort of acute illness. A potential result of adopting this higher standard is, therefore, that some patients may be judged to lack capacity who might otherwise pass a capacity test set at the lower level.

Complicating these matters, there is evidence that some patients faced with potentially dire outcomes place less importance on the provision of material information as necessary for informed consent (Scanlan, Stewart, and Kerridge 2019). That finding might seem to support an argument that COVID-19 patients, at least those at the severe end of the symptom spectrum, require disclosure of information at only the basic level as part of the assessment of capacity.

There are several grounds for rejecting such an argument. First, the materiality of risks can only be determined, self-evidently, after the fact of their disclosure. Second, whether a risk is deemed material is ultimately a subjective judgement made by the individual patient. Third, and critically, if a patient fails to understand a material risk, that failure militates against the exercise of autonomous choice, the ethical principle that assignations of mental capacity set out to protect in the first place. Plausibly, then, a failure to understand material risks, granting they have been fully communicated, should be taken as evidence of a lack of mental capacity. 
Appreciate: Retaining Treatment Information

The ability to retain information requires the patient to have a "stable understanding of the facts over time" (Biegler and Stewart 2001, 523). Patients who cannot retain information are unable to employ that information in their reasoning, frustrating the exercise of autonomous choice. It is worth noting that autonomous choice gives insight into what the patient values and what might, therefore, be in his or her best interests, something clinicians are bound to promote under the principle of beneficence. Decisions made by incapacitated patients may not reflect their values and preferences. An inability to retain material information at the time of the treatment decision suggests impaired autonomy and decisionmaking capacity. Respecting the choices of those who lack capacity, therefore, may work against both patient autonomy and beneficent care.

Reason: Weighing the Information

The patient needs to be able to weigh information in the balance - that is, consider the pros and cons to reach a decision. This might be described, roughly, as a reasoning process, but the decision itself does not have to be objectively reasonable, in the sense of being a decision that would be made by a reasonable person. According to Lord Donaldson in the case of Re T (An Adult: Refusal of Medical Treatment) [1993] Fam 95 at 113, the fact that a patient's decision is not one that "the vast majority of adults" would have made is only relevant if there are other factors for doubting the patient's capacity.

Decide: Making and Communicating a Decision

Finally, patients must be able to express their choice. Patients who cannot do so are treated as lacking capacity (see Box 1). Seriously ill COVID19 patients are likely to find it difficult or impossible to speak, due to shortness of breath or being sedated in order to be ventilated. In some cases, other methods of communication can be attempted, such as the use of body language, written information, or a letter board (Stewart and Biegler 2004).

\section{Conclusion}

Patients who present critically ill to emergency departments with COVID-19 are likely to have compromised decision-making capacity. In such cases clinical decisions are time-critical and capacity assessments need to be made quickly. The CARD approach uses brief questions to quickly establish a baseline of the patient's ability to understand and process treatment information. CARD helps clinicians respect the autonomous wishes of patients who retain capacity and protect the interests, through substitute decision-making, of patients who lack capacity. In short, CARD gives clinicians a legally defensible means of rapidly determining the mental capacity of COVID-19 patients, essential to guide urgent treatment and ensure that patients' best interests are ultimately served in the process.

Acknowledgements The authors would like to thank Professor John Coggon and Dr Camillia Kong for their helpful comments on our drafts. Any errors remain ours.

\section{References}

Bertrand, P.M., B. Pereira, M. Adda, et al. 2019. Disagreement between clinicians and score in decision-making capacity of critically ill patients. Critical Care Medicine 47(3): 337-344.

Biegler, P., and C. Stewart. 2001. Assessing competence to refuse medical treatment. The Medical Journal of Australia 174(10): 522-525.

Cave, E. 2020. Valid consent to medical treatment. Journal of Medical Ethics. ePub ahead of print, June 23. https://doi. org/10.1136/medethics-2020-106287

Chan, C., S. Yong, A. Mhaisalkar, et al. 2018. Audit of mental capacity assessment by primary care physicians versus consultation-liaison psychiatrists. East Asian Archives of Psychiatry 28(3): 95.

Curley, A., R. Murphy, R. Plunkett, and B. Kelly. 2019. Concordance of mental capacity assessments based on legal and clinical criteria: A cross-sectional study of psychiatry inpatients. Psychiatry Research 276: 160-166.

D'Souza, R.S., R. Johnson, L. Bettini, P. Schulte, and C. Burkle. 2019. Room for improvement: A systematic review and meta-analysis on the informed consent process for emergency surgery. Mayo Clinic Proceedings 94(9): 1786-1796.

Evans, K., J. Warner, and E. Jackson. 2007. How much do emergency healthcare workers know about capacity and consent? Emergency Medicine Journal 24(6): 391-393.

Grisso T., and P.S. Appelbaum. 1998. Assessing competence to consent to treatment: A guide for physicians and other health professionals. New York: Oxford University Press.

Holt, N.R., J.T. Neumann, J.J. McNeil, and A.C. Cheng. 2020. Implications of COVID-19 in an ageing population. The 
Medical Journal of Australia. ePub ahead of print, May 6. https://www.mja.com.au/journal/2020/implications-covid19-ageing-population.

Jacob, R., I. Clare, A. Holland, P.C. Watson, C. Maimaris, and M. Gunn. 2005. Self-harm, capacity, and refusal of treatment: Implications for emergency medical practice. A prospective observational study. Emergency Medicine Journal 22(11): 799-802.

Jiang, F., L. Deng. L. Zhang, Y. Cai, C. Cheung, and Z. Xia. 2020. Review of the clinical characteristics of coronavirus disease 2019 (COVID-19). Journal of General Internal Medicine 35: $1545-1549$.

Keene, A.R. 2020. Capacity in the time of Coronavirus. International Journal of Law and Psychiatry. ePub ahead of print, April 11. https://doi.org/10.1016/j.ijlp.2020.101560.

Kerridge, I., M. Lowe, and C. Stewart. 2013. Ethics and law for the health professions, 4th ed. Sydney: Federation Press.

Lamont, S., H.Y. Jeon, and M. Chiarella. 2013a. Health-care professionals' knowledge, attitudes and behaviours relating to patient capacity to consent to treatment: An integrative review. Nursing Ethics 20(6): 684-707.

. 2013b. Assessing patient capacity to consent to treatment: An integrative review of instruments and tools. Journal of Clinical Nursing 22(17-18): 2387-2403.

_.2016a. Decision-making capacity and its relationship to a legally valid consent: Ethical, legal and professional context. Journal of Law and Medicine 24(2): 371-386.

. 2016b. Documentation of capacity assessment and subsequent consent in patients identified with delirium. Journal of Bioethical Inquiry 13(4): 547-555.

- 2019. Capacity and consent: Knowledge and practice of legal and healthcare standards. Nursing Ethics 26(1): 71-83.
Mottiar, M., A. Hendin, L. Fischer, A. Rose des Ordons, and M. Hartwick. 2020. End-of-life care in patients with a highly transmissible respiratory virus: Implications for COVID-19. Canadian Journal of Anesthesia 67: 1417-1423.

Onder, G., G. Rezza, and S. Brusaferro. 2020. Case-fatality rate and characteristics of patients dying in relation to COVID-19 in Italy. JAMA 323(18): 1775-1776.

Parsons, J., and H. Johal. 2020. Best interests versus resource allocation: Could COVID-19 cloud decision-making for the cognitively impaired? Journal Medical Ethics 46(7): 447450.

Raymont, V., W. Bingley, A. Buchanan, et al. 2004. Prevalence of mental incapacity in medical inpatients and associated risk factors: Cross-sectional study. The Lancet 364(9443): 14211427.

Scanlan, C.L., C. Stewart, and I. Kerridge. 2019. Consent in the face of death. Internal Medicine Journal 49(1): 108-110.

Stewart, C. 2017. Cracks in the lintel of consent. In Tensions and traumas in health law, edited by I. Freckelton and K. Petersen, 214-233. Sydney: Federation Press

Stewart, C., and P. Biegler. 2004. A primer on the law of competence to refuse medical treatment. Australian Law Journal 78(5): 325-342.

Thevarajan, I., K.L. Buising, and B.C. Cowie. 2020. Clinical presentation and management of COVID-19. The Medical Journal of Australia 213(3): 134-139.

Publisher's note Springer Nature remains neutral with regard to jurisdictional claims in published maps and institutional affiliations. 